\title{
Regras em uma resolução da Universidade Federal de Mato Grosso do Sul e seus efeitos no comportamento de alunos e professores*
}

\section{Rules in a resolution of federal university of Mato Grosso do Sul and its effects on the behavior of students and teachers}

Ludmila Zatorre Dantas ${ }^{1}$ Ronaldo Rodrigues Teixeira Júnior ${ }^{2}$
* Recebido em: 05/10/2013 Aprovado em: 09/06/2014

1 Graduada em Psicologia pela Universidade Federal de Mato Grosso do Sul (UFMS). Endereço eletrônico: ludmila.dantas@yahoo.com.br.

2 Doutor em Teoria e Pesquisa do Comportamento pela Universidade Federal do Pará (UFPA) e professor adjunto da Universidade Federal do Mato Grosso do Sul (UFMS). Endereço eletrônico: ronaldortj@yahoo.com.br.

\section{Resumo}

Regras são elementos importantes na manutenção de práticas culturais. Assim, falhas em sua formulação podem interferir em seu seguimento. Este trabalho analisou seis artigos e um parágrafo presentes na Resolução № 214 da UFMS referente às normas de ensino na graduação e possíveis efeitos nos comportamentos dos alunos e professores de Psicologia da instituição. A investigação desta resolução serviu como exemplo para analisar o comportamento de seguir regras sociais. Para isso, realizou-se: separação dos trechos da resolução em grupos, de acordo com o tema ao qual se referiam; análise de cada trecho utilizando-se a tríplice contingência; descrição dos possíveis objetivos de cada trecho; e relato do que se observou nos comportamentos de alunos e professores de Psicologia. Todos os trechos analisados foram considerados descrições incompletas de contingências, uma vez que, em geral, não indicavam consequências para o seguimento da regra, além do fato de não ser amplamente divulgada entre alunos e professores. Supõe-se que isso pode ser um dos fatores para o não cumprimento da resolução.

Palavras-chave: Leis. Análise funcional. Tríplice contingência. Comportamento. Alunos. Professores.

\begin{abstract}
Rules are important elements in maintaining cultural practices. Thus, failures in its formulation might interfere with its action. This study analyzed six articles and a paragraph of Resolution No. 214 of UFMS relating to standards of teaching in college and its effectiveness in controlling the behavior of the students and teachers of Psychology of the institution. The resolution was used as a basis for analyzing the behavior of following rules. For it was held: separation of excerpts from the resolution in groups, according to the subject to which they referred; analysis of each section using the three-term contingency; description of the possible objectives of each section; and report on what was observed in the behavior of students and teachers of Psychology of the institution. The investigation of this resolution served as a case study to exemplify an analysis of institutional use of social rules. All sections analyzed were considered incomplete descriptions of contingencies, since, in general, did not indicate consequences to follow the rule, and the fact not being widely disseminated among students and professors. It is assumed that this can be one of the factors for noncompliance resolution.
\end{abstract}

Keywords: Laws. Functional analysis. Three-term contingency. Behavior. Students. Teachers. 


\section{Introdução}

Skinner (1966) apresentou uma definição para o termo "regras". Segundo ele, regras seriam estímulos discriminativos que descrevem contingências. Estudos posteriores sobre o tema aperfeiçoaram tal definição com base em investigações experimentais e teóricas (ALBUQUERQUE, 2001; BAUM, 2006; SCHLINGER; BLAKELY, 1987; ZETTLE; HAYES, 1982). Uma das definições mais aceita é a de Albuquerque (2001). Segundo ele, regras são consideradas estímulos verbais antecedentes que descrevem contingências e apresentam múltiplas funções. Dentre estas, podem-se destacar: a função de estímulo discriminativo, a de estímulo alterador de função e a de operação estabelecedora (ALBUQUERQUE; PARACAMPO, 2010). Nesse sentido:

[...] instruções, avisos, orientações, conselhos, ordens, leis, etc. seriam exemplos particulares de regras, uma vez que todos podem descrever contingências. Isto é, podem descrever as relações entre os eventos que antecedem o comportamento, o próprio comportamento e suas prováveis consequências (ALBUQUERQUE, 2001, p. 133).

Regras, por serem estímulos verbais, são produtos do convívio social, e, portanto, dependentes da comunidade verbal, na qual são formuladas e ensinadas. Segundo Matos (2001), é principalmente o ouvinte que define a regra como comportamento verbal, pois é ele que irá seguir ou não a regra estipulada. Porém, estudos sobre regras podem englobar tanto o comportamento do falante, emissor da regra, quanto o comportamento do ouvinte.

A aprendizagem por regras pode ser considerada uma forma de aprendizagem fundamental, havendo registros históricos de sua utilização desde o aparecimento da escrita, tais como: as Leis das Doze Tábuas, o Código de Hamurabi, a Bíblia, etc. Todavia, a aprendizagem por regras não substitui nenhum dos outros tipos de aprendizagem, como a aprendizagem por imitação, por observação ou por contato direto com as contingências, assim como nenhum dos outros tipos de aprendizagem substitui a aprendizagem por regras; pelo contrário, as diversas formas de aprendizagem se complementam, o que pressupõe que devem ser utilizadas em conjunto para uma aprendizagem mais eficaz (CASTANHEIRA, 2001).

Regras são entendidas como variáveis importantes que possibilitam o controle do comportamento humano, contudo, não são causas de comportamentos. Na Análise do Comportamento, os indivíduos não se comportam como o fazem porque seguem regras, eles seguem regras porque aprenderam a se comportar dessa maneira. Afinal, o próprio seguimento de regras é um comportamento e, portanto, foi estabelecido no contexto de uma história de reforçamento, podendo ser controlado e alterado. O controle por regras advém da interação social, o que faz com que as regras sejam subprodutos dessa interação e como tal, não devem ser tratadas como causas últimas do comportamento (MATOS, 2001).

\subsection{Comportamento governado por regras e o comportamento modelado por contingências}

Há algumas semelhanças entre o comportamento governado por regras e o comportamento modelado por contingências, uma vez que o comportamento governado por regras também depende de contingências ambientais para ocorrer, além de ambos poderem possuir topografias semelhantes. Todavia, a diferença principal entre eles está no fato de que ocorrem a partir de condições antecedentes distintas, sendo, então, operantes distintos (SKINNER, 1980).

O comportamento governado por regras está sob o controle de uma descrição verbal feita pelo falante, independentemente das consequências imediatas, isso porque tal comportamento pode ocorrer antes mesmo de ter contato com as consequências. "Ou seja, as regras podem estabelecer um comportamento apropriado às contingências de reforço sem que este comportamento tenha sido diretamente exposto a essas contingências." (ALBUQUERQUE, 2001, p. 138). Assim, o comportamento governado por regras depende mais de contingências sociais, do que de contingências não sociais devido a sua utilização e relevância na cultura. Em outras palavras, nesse tipo de comportamento, a aprendizagem ocorre pelo seguimento de uma descrição verbal (seja oral ou escrita) feita por outro indivíduo, como por exemplo, "faça desta forma e se sairá melhor". Desse modo, o seguimento ou não da regra não se trata apenas de um comportamento emitido pelo ouvinte, como também é uma consequência para o comportamento do falante. Por isso, os participantes de um episódio verbal que contenha regras devem apresentar repertórios verbais comuns (MATOS, 2001).

Já o comportamento modelado por contingências está sob o controle direto de consequências imediatas, independente de uma descrição verbal antecedente. Tal descrição pode estar presente, mas não exercerá controle sobre o comportamento. É o que pode ser chamado de 
"aprendizagem pela experiência" (PARACAMPO; ALBUQUERQUE, 2005). Em resumo, portanto, "o comportamento controlado por regras depende do comportamento verbal de outra pessoa (o falante), enquanto o comportamento modelado [pelas contingências] não requer outra pessoa, requer somente interação com reforço não social." (BAUM, 2006, p. 166). Adicionalmente, além dessas duas modalidades de comportamento isoladas, em algumas situações, ambos os comportamentos podem estar presentes. É o que se denomina interação entre regras e contingências:

[...] quando regras correspondem às contingências de reforço (isto é, quando o comportamento especificado pela regra é semelhante ao comportamento que produz reforço), pode-se dizer que a emissão do comportamento previamente especificado é controlada pela regra, apenas antes que as consequências produzidas por este comportamento tenham oportunidade de exercer algum efeito sobre ele. Depois disso, o comportamento observado passa a ser controlado pela interação entre as regras e as contingências de reforço para o seguimento da regra. (ALBUQUERQUE, 2001, p. 139)

\subsection{Vantagens e desvantagens da aprendizagem por regras}

Uma primeira vantagem da aprendizagem por regras é o fato de ela ser em geral mais rápida do que a aprendizagem por contingências. Com as regras, consegue-se que o indivíduo apresente o comportamento desejado sem que ele tenha que passar diretamente por várias consequências em sua história, favorecendo, assim, a aprendizagem de comportamentos mais complexos. Isso ocorre porque a regra, como uma descrição verbal, é mais específica em relação ao comportamento a ser apresentado (CASTANHEIRA, 2001).

Outro ponto importante é que as regras estabelecem e mantêm comportamentos que não produzem consequências reforçadoras imediatas, o que as torna úteis para complementar contingências fracas, remotas e complexas (BAUM, 2006). Um exemplo simples pode ser ensinar uma criança a estudar. Geralmente esta não é uma tarefa reforçadora para muitas crianças, pois demora algum tempo, às vezes, até anos, para que ela entre em contato com reforços naturais provindos desse comportamento, porém, a maioria dos reforçadores relacionados ao comportamento de estudar é arbitrária, são exemplos desse tipo de reforçador frases como: "estudar é importante para que se tenha uma boa vida", "se você estudar e trabalhar poderá comprar as coisas que deseja”, etc.

Dentre as vantagens das regras, observa-se também que com o seu uso, situações aversivas presentes em uma aprendizagem pelas contingências podem ser evitadas. Por essa razão, o indivíduo não precisará entrar em contato direto com algumas consequências aversivas (CASTANHEIRA, 2001; NICO, 1999). Nesta situação, uma criança não precisa entrar em contato com a aversividade do frio, por exemplo, para aprender que, quando o clima não estiver bom, ela deverá colocar roupas apropriadas para aquele contexto. Sua mãe pode simplesmente lhe dizer: "está sem sol e ventando muito, você deve colocar seu casaco".

Apesar das vantagens na utilização das regras, este tipo de controle tem também suas desvantagens. $\mathrm{O}$ fato de o indivíduo ficar somente sob o controle de regras pode não gerar um desempenho tão refinado quando comparado a um comportamento sob controle direto das contingências, pois, para esse refinamento ocorrer, é necessária uma maior variação comportamental e exposição a diferentes consequências, que, nesse caso, pode ser comprometida pelo seguimento excessivo de regras (MATOS, 2001; PARACAMPO; ALBUQUERQUE, 2005; TEIXEIRA JÚNIOR, 2007). Isso se relaciona a outra desvantagem da aprendizagem por regras, que tem sido chamada de "insensibilidade" às consequências, isto é, o comportamento governado por regras tenderia a ficar mais controlado por antecedentes verbais, que em geral são mantidas por reforço social e descrevem relações de longo prazo, do que por outras consequências imediatas, tornando o indivíduo menos adaptável a novas situações (NICO, 1999; TEIXEIRA JÚNIOR; BRITO; PARACAMPO, 2011). Essa situação pode ser evidenciada quando contingências não condizem com a regra (regra discrepante) e o indivíduo continua a apresentar a resposta descrita pela regra, mesmo sem produzir reforçadores. Isso pode levar a emissão de comportamentos inflexíveis ou ineficientes, que pelo seguimento da regra teriam sido reforçados no passado, e continuariam a ser realizados (CALIXTO, 2009).

O comportamento modelado por contingências, por sua vez, apesar de ser mais lento e eventualmente apresentar situações aversivas, também é mais variável e flexível, pois se altera conforme as mudanças nas contingências, o que estabelece um repertório comportamental mais variado, e, portanto, mais adaptável ao ambiente. $\mathrm{O}$ ideal seria uma aprendizagem que contemplasse tanto o 
controle por regras quanto por contingências, pois enquanto a aprendizagem por regras é mais rápida e menos aversiva, ela também é mais arbitrária e pontual (CASTANHEIRA, 2001).

\subsection{Alguns fatores que afetam o seguimento de re- gras}

Após definir as regras, estabelecer diferenças entre o comportamento governado por regras e modelado por contingências, e listar suas vantagens e desvantagens resta saber quais fatores favorecem ou não seu seguimento. Um dos elementos importantes a ser considerado é se a regra especifica os termos de uma contingência, ou seja, antecedente, resposta e consequência. Esses termos se referem a propriedades formais da regra, ou seja, como a regra deve ser formulada e apresentada ao indivíduo de forma que ele emita uma determinada resposta. Uma regra claramente descrita pode favorecer que essa resposta ocorra, enquanto uma regra sem a especificação desses componentes pode dificultar que ela seja emitida (TEIXEIRA JÚNIOR, 2011; TODOROV et al., 2004).

Segundo Matos (2001), quanto mais específicas as regras, maior aderência ao seu seguimento e mais preciso o desempenho, mas isso não significa que a regra será seguida caso todos os elementos estejam presente na descrição da contingência (ALBUQUERQUE, 2001). Por exemplo, se uma regra for muito complexa ou extensa, mesmo se tiver todos os componentes da contingência, ela poderá confundir o ouvinte e comprometer a emissão da resposta (ALBUQUERQUE; FERREIRA, 2001; TEIXEIRA JÚNIOR, 2011).

Outro aspecto formal a ser considerado é que uma regra fornecida no formato de uma ordem ou conselho, por exemplo, também pode produzir diferentes efeitos sobre o seu seguimento (CASTANHEIRA, 2001). A ordem geralmente tem como consequência uma punição apresentada pelo falante caso ela não seja seguida, e quando é seguida, o ouvinte geralmente reforça o comportamento do emissor da regra. As leis são um exemplo desse tipo de regra, considerando que o governo é quem detém o poder de liberar a consequência descrita, que quase sempre é punitiva. O conselho, por sua vez, envolve reforçadores naturais que beneficiam mais o ouvinte, isto é, o próprio indivíduo entra em contato com os reforçadores produzidos pelo seu comportamento de seguir a regra. Retomando o exemplo da mãe que diz à criança para colocar um casaco, o seguimento da regra será na- turalmente reforçador, pois cessará o frio e a criança se sentirá mais aquecida. Isso provavelmente fará com que ela siga mais conselhos da mãe no futuro. Desse modo, é possível afirmar que

[...] no primeiro caso, as regras seriam seguidas porque o comportamento de seguir regras similares evitou punição social no passado. Já no segundo caso, as regras seriam seguidas porque o comportamento de seguir regras similares foi positivamente reforçado no passado. (PARACAMPO; ALBUQUERQUE, 2005, p. 230)

Além da ordem e conselho, regras podem ser apresentadas de modo afirmativo ou interrogativo (MATOS, 2001). No primeiro, a regra será descrita de maneira clara, direta e simples, como por exemplo: "você não pode fumar neste local porque aqui tem alguns produtos inflamáveis", enquanto no segundo, ela é feita como uma pergunta: “você poderia não fumar aqui?”. Embora nos deparemos frequentemente com o segundo exemplo, esta pode não ser maneira mais adequada de se fornecer uma regra, pois além de não conter os elementos principais da contingência, essa regra pode fazer com que o ouvinte não tenha certeza sobre qual comportamento deve emitir ou em que situação deve fazê-lo, podendo envolver também a coerção do falante sobre o ouvinte.

Assim, as variáveis sociais são aspectos importantes que interferem no seguimento de regras. Se a regra é fornecida por um agente que tem controle sobre o comportamento do ouvinte, como pai, mãe, ou o próprio governo, no caso de leis, é mais provável que a pessoa a siga, dependendo de sua história passada em relação a esses agentes (MATOS, 2001). O fato de essa pessoa ou agente de controle também se encontrar presente ou não, monitorando a ação do ouvinte, tem-se mostrado uma variável relevante em pesquisas da área (BARRETT et al., 1987; CERUTTI, 1994). Tal como consequências sociais, outros tipos de consequências interferem no seguimento de regras, bem como a história de reforçamento que o indivíduo possui em seguir regras correspondentes ou discrepantes (PARACAMPO; ALBUQUERQUE, 2005).

\subsection{Regras e cultura}

[O meio cultural ensina] ao indivíduo o que pode e o que não pode fazer, dando-lhe normas e determinando a amplitude dos comportamentos sociais permitidos, prescritos ou proibidos. Ensina-lhe a linguagem que deve falar, dá-lhe seus padrões de beleza e arte, de boa ou má conduta; coloca diante dele um quadro de personalidade ideal que deve imitar e procurar ser. Em tudo isso, estão presentes as leis fundamentais 
do comportamento. (KELLER; SCHOENFELD, 1973, p. 382)

Toda cultura faz o uso de regras para ensinar os indivíduos como devem se comportar e para manter esses comportamentos. Desse modo, elas podem ser vistas como elementos importantes na manutenção de práticas culturais, e na convivência em sociedade (ALBUQUERQUE, 2005). Isso favorece o autocontrole por parte dos membros da cultura; esse tipo de controle é especialmente importante não só para sua própria sobrevivência, mas também para sobrevivência do grupo.

A respeito desse autocontrole gerado no convívio social, Baum (2006) afirma que o comportamento governado por regras sempre apresenta duas contingências: uma de longo prazo e outra de curto prazo. Segundo o Baum (2006, p. 172), a de longo prazo trata-se da "razão primeira da regra", ou seja, envolveria aquela consequência produzida pelo seguimento da regra distante no tempo, ou em outras palavras, o resultado postergado desse seguimento. A de curto prazo, por outro lado, envolveria consequências próximas da regra, envolvendo geralmente reforçadores frequentes e imediatos para favorecer seu seguimento. Nas contingências próximas, geralmente o reforço é arbitrário, como aprovação, elogios, atenção, notas, etc., enquanto nas contingências últimas, geralmente os reforçadores estão relacionadas à sobrevivência e à reprodução como preservar a saúde parando de fumar ou fazendo uma dieta. Porém esse é o problema com consequências remotas ou atrasadas, "se as ocasiões para a ocorrência de comportamento controlado por regras forem muito infrequentes, então a transição para o reforço último pode nunca vir a ocorrer." (BAUM, 2006, p. 176). Isso justifica o aperfeiçoamento do conhecimento acerca do controle por regras para que estas sejam efetivas tanto para a regulação do comportamento em um nível individual quanto para a sociedade que as estabelece e espera que sejam cumpridas.

Como forma de unificar a sociedade e manter a sobrevivência da cultura, o grupo disponibiliza tanto de reforço como de punição para controlar o comportamento de seus membros. Quando o grupo se organiza de maneira institucionalizada, pode exercer um controle mais preciso sobre o comportamento de seus membros, e ser denominado como uma agência controladora (SKINNER, 2003). Uma dessas agências descritas por Skinner no livro Ciência e Comportamento Humano foi "Governo e lei", sendo que o autor define governo como o uso do poder para punir e utiliza-se das classificações "legal" e "ilegal" com o propósito de reforço, em maior parte negativo, ou punição; já lei seria definida como uma codificação dos procedimentos controladores do governo, e que possui duas funções: especificar o comportamento e uma consequência atrelada a ele, geralmente punitiva. Para o autor, "[a] lei então é um enunciado de uma contingência de reforço mantida por uma agência governamental." (p. 370). A partir das definições de lei e regra feitas por Skinner (2003), poderíamos afirmar que leis seriam regras formuladas pela agência controladora denominada governo, e considerando a proximidade entre essas definições, serão relatados a seguir alguns estudos que têm investigado essa relação.

\subsection{Estudos de leis como regras pela Análise do Comportamento}

Alguns estudos recentes analisaram leis brasileiras a partir do enfoque da Análise do Comportamento. O primeiro estudo nesse sentido foi feito por Todorov (1987), intitulado A Constituição como metacontingência. O autor aponta que as leis são regras de conduta dos indivíduos que geralmente são punitivas. Sobre sua eficiência, Todorov afirma que alguns dos artigos descritos na constituição brasileira apresentam problemas quando aplicados à educação, pois são postulados objetivos muito gerais, o que torna a regra mais difícil de ser seguida.

Posteriormente, outros estudos foram realizados. Todorov et al. (2004) analisaram o Estatuto da Criança e do Adolescente (ECA) como metacontingência. O objetivo do trabalho foi identificar a tríplice contingência em artigos da lei, ou seja, o antecedente, o comportamento e consequentes como forma de verificação da eficiência da lei. Foi observado que a maioria dos artigos era agrupada em grupos, e esse agrupamento de artigos que formavam uma contingência não estavam em ordem numérica, pois os elementos da tríplice contingência não se encontravam em artigos próximos. Portanto, foi evidenciado que a lei não define bem as contingências, pois apesar de poderem ser identificadas, elas não estão bem organizadas na formulação da lei.

Foi realizada também a Descrição e análise de contingências na proposta de Estatuto da Pessoa com Deficiência por Almeida-Verdu et al. (2009), na qual foi feita a descrição dos fenômenos da inclusão a partir das leis presentes nesse estatuto e do referencial teórico da Análise do Comportamento, fazendo uso do conceito 
de metacontingência. $\mathrm{O}$ método utilizado foi semelhante aos estudos anteriores: identificação de antecedentes, comportamentos e consequentes nos artigos da lei. $\mathrm{O}$ objetivo do Estatuto apontado pelos autores foi o de regular o comportamento do grupo a partir de regras, porém os autores concluíram que as leis analisadas não eram claras e específicas, o que dificultava a aplicação e seguimento da regra estabelecida, no caso, o artigo descrito pela lei.

Cabral (2011) publicou outro trabalho a esse respeito, intitulado Contingências e metacontingência na lei Maria da Penha. Foram realizadas análises contingenciais dos artigos distribuídos na lei, de modo a identificar os comportamentos descritos nos artigos, assim como antecedentes e consequentes. Foram realizadas análises das metacontingências presentes na lei, seu produto agregado e a consequência cultural. Entre os 47 artigos dispostos na lei, não foi encontrado nenhum que apresentasse uma contingência completa, com seus três componentes. Apesar disso, a autora relata que esta lei em particular trata-se de uma norma descritiva para evitar a violência doméstica com mudanças no meio social por meio de políticas públicas voltadas ao atendimento da vítima e do agressor, e está diretamente entrelaçada a outras leis mais gerais sobre a violência, como por exemplo, o Código Penal. Assim, mesmo que não apresente nenhuma contingência completa, o autor alega que a lei tem-se mostrado efetiva, pois tem ajudado na diminuição do número de casos de violência doméstica contra a mulher no Brasil.

Considerando que todos os estudos descritos apresentam falhas na formulação de leis e que isso pode interferir no seu seguimento como regras, este trabalho teve como objetivo analisar seis artigos e um parágrafo presentes na Resolução No 214, de 17 de dezembro de 2009 da Universidade Federal de Mato Grosso do Sul (UFMS), referente às normas de ensino na graduação como forma de avaliar seus possíveis efeitos no comportamento de alunos e professores de Psicologia da instituição.

\section{Método}

\subsection{Objeto do estudo}

A resolução n 214, de 17 de dezembro de $2009^{3}$ da

3 Após a conclusão desse trabalho, a resolução $\mathrm{N}^{\circ} 214$, de 17 de dezembro de 2009 foi revogada e atualmente a resolução $N^{\circ} 269$, de 1 de agosto de 2013 encontra-se em vigor na UFMS.
UFMS consiste em XX capítulos, III Seções e 65 artigos. O documento analisado tem como objetivo normatizar as práticas discentes e docentes em relação às avaliações, frequências e aprovações. Alguns pontos foram considerados na escolha dessa resolução: o documento trata da relação professor-aluno; o documento pertence à universidade e é de fácil acesso; a autora é discente na instituição e, portanto, tem contato direto no cotidiano com as práticas descritas na resolução. Os seis artigos e o parágrafo escolhidos foram aqueles que a autora considerou mais claros para observação de respostas de cumprimento ou não por alunos e professores do curso de Psicologia da instituição.

\subsection{Instrumento}

Para a realização da análise dos artigos, a tríplice contingência foi utilizada como instrumento, pois permite analisar funcionalmente seu conteúdo (CABRAL, 2011) e identificar três elementos principais presentes na contingência descrita pelo artigo: antecedente, resposta e consequência. Dessa forma, é possível uma análise mais detalhada dos aspectos formais da regra e suas respectivas funções, bem como das variáveis que controlam o comportamento do ouvinte (seguidor da regra).

Os termos da tríplice contingência foram considerados de acordo com as seguintes definições:

Antecedente: considerado como o contexto no qual a resposta ocorre (SKINNER, 2006).

Resposta: é a ação do organismo, e é por meio dela que o indivíduo opera no ambiente. Ela é parte do comportamento do indivíduo (SKINNER, 2003).

Consequência: é a alteração do ambiente provocada pela resposta do indivíduo. Pode resultar desta ou ser produzida por ela. É ela que seleciona a resposta (CATANIA, 1999; SKINNER, 2006).

\subsection{Procedimento}

O procedimento consistiu em quatro etapas: (a) separação dos trechos da resolução em grupos, de acordo com o tema ao qual se referiam; (b) análise de cada trecho utilizando-se a tríplice contingência; (c) descrição dos possíveis objetivos de cada trecho da resolução; e (d) relato do que a autora observa no comportamento de alunos e professores do curso de Psicologia da instituição. Assim, os trechos da resolução foram agrupados em cinco diferentes grupos de acordo com o que especificavam (plano de ensino, matrícula, frequência, avaliações e san- 
ções gerais), sendo que em cada um deles foi identificado antecedentes, respostas e consequências. Posteriormente, foi realizada uma comparação entre as contingências descritas nos artigos e as práticas no ambiente da instituição em relação a cada artigo, como forma de avaliar o seguimento da regra descrita na norma.

O Grupo 1 se refere ao Plano de Ensino, tendo sido analisados os artigos 11 e 13; o Grupo 2 se refere à Matrícula, tendo sido analisado apenas o artigo 21; o Grupo 3 se refere à Frequência, tendo sido analisado apenas o artigo 50; o Grupo 4 se refere às Avaliações, tendo sido analisado o $4^{\circ}$ parágrafo do artigo 51 e o artigo 57; e o Grupo 5 se refere às Sanções Gerais, tendo sido analisado apenas o artigo 64 .

\section{Resultados}

\subsection{Grupo 1 - Plano de Ensino}

Art. 11. Cada disciplina deverá ter um Plano de Ensino, contendo obrigatoriamente:

I - identificação;

II - objetivos;

III - ementa;

IV - programa;

$\mathrm{V}$ - procedimentos de ensino;

VI - recursos;

VII - avaliação;

VIII - atividade pedagógica de recuperação de desempenho em avaliações;

IX - bibliografia; e

X - assinatura do professor; (UFMS, 2010)

$\mathrm{O}$ artigo especifica um estímulo discriminativo (Sd), ou seja, um antecedente, ao apontar que cada disciplina deverá ter um plano de ensino, e especifica uma resposta que deve ser emitida pelo professor: formular o plano de ensino de cada disciplina conforme os dez itens especificados. Assim, o artigo apresenta dois elementos de uma tríplice contingência: resposta e antecedente, mas não apresenta consequências para o cumprimento ou não da regra, portanto, como as consequências encontram-se ausentes, $\mathrm{o}$ artigo trata-se de uma descrição incompleta de contingências.

A regra descrita é útil tanto aos docentes quanto aos discentes que cursam a disciplina, pois o professor poderá organizar antecipadamente o conteúdo a ser ministrado, especificando os temas que serão tratados, a maneira com que as aulas serão apresentadas, formas de avaliação, livros e textos a serem utilizados, autores relevantes na área e caso necessário, uma forma de recuperação de desempenho; itens igualmente relevantes aos alunos e futuros profissionais, que poderão se organizarem melhor para a disciplina.

Apesar da utilidade e possibilidade de eficiência ao seguimento da regra estipulada, na instituição isso geralmente não acontece. São poucos professores que elaboram o plano de ensino e, dentre esses, ainda são raros aqueles que elencam os dez itens da lista, usualmente os itens presentes são aqueles que podemos chamar de "itens básicos", como: objetivo, ementa, avaliação e bibliografia, faltando, portanto, a maioria daqueles requisitados nas normas institucionais.

"Art. 13. O professor da disciplina deverá apresentar e disponibilizar o Plano de Ensino, aos acadêmicos, na primeira aula." (UFMS, 2010).

$\mathrm{O}$ artigo descreve duas respostas que devem ser emitidas pelo professor: apresentar e disponibilizar o plano de ensino aos acadêmicos em uma situação específica, ou seja, na primeira aula. Desse modo, foram identificados dois elementos da contingência: um antecedente (contexto ou situação) e respostas (o que deve ser feito), não apresentando consequências para o cumprimento ou não da regra. Por isso, a regra descrita foi considerada como uma descrição incompleta de contingências, por conter apenas dois elementos da contingência.

Sobre a relevância e utilidade na formulação dessa regra, são levados em consideração melhor preparação tanto do professor quanto do aluno em relação à disciplina, e melhor organização do material e procedimentos que serão utilizados, conhecimento prévio acerca dos textos e autores que serão referenciados, e formas de avaliação daquela disciplina específica. Além disso, essas regras também são importantes para que o conteúdo ministrado e avaliações não mudem aleatoriamente durante $o$ andamento da disciplina.

Em geral, poucos professores cumprem essa norma, mas quando isso é feito, a maioria não apresenta o plano de ensino em sala, apenas o disponibiliza em endereço eletrônico para a turma. Normalmente isso também não é feito no primeiro dia de aula, como consta no artigo, o mais comum é o professor disponibilizar o plano de ensino após o início das aulas, com a disciplina já em andamento. Assim, apenas a segunda resposta descrita pela regra costuma ser seguida, a de disponibilização do plano 
de ensino, porém em contexto diferente do especificado: endereço eletrônico e não sala de aula. Uma apresentação propriamente dita dificilmente é realizada.

\subsection{Grupo 2 - Matrícula}

Art. 21. Ao realizar a matrícula, o acadêmico se compromete a respeitar e cumprir as normas específicas, regimentais e estatutárias da UFMS (UFMS, 2010).

Neste artigo, foram identificados dois elementos da contingência: antecedente e resposta. $\mathrm{O}$ antecedente trata-se do ato de matrícula, descrito ao início da regra, ou seja, é a situação em que a resposta ocorre, enquanto a resposta é o comprometimento de "respeitar e cumprir as normas específicas, regimentais e estatutárias" da instituição. $\mathrm{O}$ terceiro elemento da contingência, a consequência, está ausente no artigo acima, e, portanto, ele apresenta uma descrição incompleta de contingências.

$\mathrm{O}$ artigo prescreve ao acadêmico comprometimento a respeito das normas e regimentos institucionais. Desse modo, a relevância dessa prescrição se deve ao conhecimento, por parte do discente do que ele pode ou não fazer de acordo com as regras presentes em regulamentos da instituição em que ele frequenta e na qual realiza suas atividades acadêmicas. Por tal razão, seria recomendado que ele fosse apresentado a essas normas, como forma de ter mais clareza sobre seus direitos e deveres como aluno.

Quando os alunos realizam a matrícula, as informações fornecidas são, basicamente: quando iniciam as aulas e onde são as aulas do curso no qual se matriculou. Nada é informado ao aluno a respeito de normas e regimentos da instituição. Além disso, o próprio artigo não especifica quais seriam essas normas, para eventual dúvida do aluno a respeito delas, o que demonstra que tal descrição é vaga, sem clareza de quais comportamentos devem ser emitidos e em quais situações.

\subsection{Grupo 3 - Frequência}

Art. 50. Ao final de cada mês o professor responsável pela disciplina deverá divulgar para os acadêmicos o número de presenças às aulas efetivamente ministradas no período (UFMS, 2010).

$\mathrm{O}$ artigo acima o trecho "ao final de cada mês" foi identificado como antecedente, enquanto o resto da sentença foi identificado como resposta prescrita para ser emitida pelo professor responsável pela disciplina. Assim, não há a apresentação de consequências em relação ao seguimento ou não da regra, caracterizando essa descrição de contingências como incompleta.

Ao acadêmico é relevante o conhecimento sobre sua frequência na disciplina, já que a maior parte dos cursos da instituição são presenciais e, portanto, exigem $75 \%$ de presença durante o semestre. Assim, essa prática é importante para que aluno e professor acompanhem o número de faltas durante o semestre, evitando erros e imprevistos, de modo que o aluno não exceda o limite de faltas.

A respeito do que acontece na instituição, os professores não emitem a resposta requerida pelo artigo, embora costumem apresentar o número de faltas ao aluno quando ele o solicita. Mas quando isso não ocorre, o professor geralmente divulga o número de faltas próximo ao final do semestre, o que algumas vezes não permite reverter a situação se já ultrapassou o limite permitido. Nesse caso, só resta ao aluno conversar com o professor e tentar rever sua frequência, mas caso não haja entendimento, o aluno pode ser reprovado e ter que fazer a matéria no semestre seguinte.

\subsection{Grupo 4 - Avaliações}

$\$ 4^{\circ}$. do Art. 51. Em cada disciplina, a programação do Plano de Ensino deverá prever, no mínimo, duas avaliações obrigatórias e uma avaliação optativa substitutiva (UFMS, 2010).

É possível identificar, por meio desta oração, apenas dois elementos de tríplice contingência: antecedente e resposta. $\mathrm{O}$ antecedente se refere ao contexto de realização disciplina e seu plano de ensino; enquanto a resposta, a ser emitida pelo professor, é a realização de no mínimo duas avaliações obrigatórias e uma substitutiva. Quanto às consequências referentes ao seguimento ou não dessa regra, o artigo não as descreve, portanto, tal descrição de contingências foi considerada incompleta.

As avaliações do semestre são de suma importância para a disciplina e com o estabelecimento de no mínimo duas avaliações, alunos e professores podem observar os resultados da primeira avaliação para então fazer modificações na aula (professor) ou na rotina de estudos (aluno) como forma de melhorar o processo de ensino-aprendizagem. Desse modo, também se evita apenas uma prova acumulada com todo o conteúdo, e um aluno que não alcançou a média requerida na primeira avaliação tem a oportunidade de recuperá-la na segunda. Se mesmo assim o aluno não alcançar média para aprovação, ele ainda tem mais uma chance, fazendo a prova optativa substitutiva, também prevista no mesmo parágrafo. 
Geralmente os docentes realizam pelo menos duas avaliações durante o semestre, porém muitos não dão oportunidade de prova optativa substitutiva para todos os alunos, talvez pela falta de uma descrição mais clara para sua realização nesse trecho. No início da resolução, a avaliação optativa substitutiva aparece definida como "aquela que, por opção do acadêmico, substitui a menor nota;", porém a maioria dos professores tende a não realizar essa avaliação quando todos os alunos são aprovados na disciplina. A opção de fazê-la normalmente ocorre quando algum dos alunos não alcança a média para aprovação, embora reste a dúvida se outros alunos podem fazê-la para tentar aumentar sua nota final na disciplina ou se estes podem ter sua nota diminuída caso sua realização implique uma nota abaixo da que foi substituída.

Art. 57. O professor deverá divulgar:

I - a solução padrão das avaliações escritas e orais - até a aula seguinte após a realização de cada avaliação; e

II - as notas das provas e trabalhos acadêmicos - até dez dias úteis após a sua realização, respeitadas as datas estabelecidas para o término do período letivo. (UFMS, 2010).

Foram identificados apenas dois dos termos que compõem a tríplice contingência, tanto no inciso I quanto no II do artigo acima. O artigo inicia estabelecendo que o professor "deverá divulgar" as seguintes respostas: "solução padrão das avaliações escritas e orais" (inciso I); e "nota das provas e trabalhos acadêmicos" (inciso II). Para o inciso I, o contexto para emissão da resposta é "até a aula seguinte após a realização de cada avaliação"; para o inciso II, o contexto para emissão da resposta é "até dez dias úteis após sua realização [...]”(UFMS, 2010). Essa norma não prevê consequências para seu seguimento ou não, mostrando ser uma descrição incompleta das contingências.

A divulgação das respostas corretas das avaliações e das notas obtidas é de grande relevância para os alunos, pois permite que entrem em contato com suas dificuldades e acertos, como forma de avaliar seu desempenho na disciplina. Isso favorece a maior organização do aluno quanto à sua rotina de estudos, tornando-o capaz de identificar se precisa de uma nota maior ou não na próxima avaliação, alterando seu comportamento de estudo de acordo com o resultado obtido.

De maneira geral, os prazos estabelecidos neste artigo raramente são seguidos pelos docentes da instituição, sendo que muitos professores, inclusive, realizam a segunda avaliação sem fornecer aos alunos a nota da primeira. Além disso, a maioria dos docentes não tem costume de divulgar a correção das avaliações, fazendo com que muitas vezes os alunos não entendam o que erraram ou por que tiveram uma nota maior ou menor que outros colegas. O mais comum é a divulgação de notas com atraso em um período muito próximo ao fim do ano letivo pela internet, o qual torna mais difícil as correções e possíveis alterações de nota, caso alguma precise ser revista.

\subsection{Grupo 5 - Sanções Gerais}

Art. 64. O não cumprimento das obrigações deste Regulamento implica a aplicação das penalidades, de acordo com os regulamentos específicos (UFMS, 2010).

Neste artigo foram identificadas consequências gerais que se referem ao não seguimento de todas as normas descritas no documento, e não consequências específicas acerca de respostas e contextos específicos de cada artigo. A resposta foi identificada como "o não cumprimento das obrigações deste Regulamento", o que também não fica claramente definida, uma vez que se encontra na negativa e não especifica quais ou quantas obrigações precisam ser descumpridas para gerar quais consequências. Assim, apesar de sinalizar que o não cumprimento das normas, ou algumas delas, implica a aplicação de penalidades, $\mathrm{o}$ artigo não informa quais penalidades são essas, e já que estão em regulamentos específicos, quais são eles. Considerando a ausência da descrição de contexto para emissão de uma resposta pouco clara com consequências, também, pouco claras, pode-se considerar que o artigo representa uma descrição vaga e incompleta de uma contingência.

A existência de consequências para o não cumprimento das obrigações dessa resolução é um aspecto importante para a manutenção de certa ordem na condução de atividades acadêmicas por alunos e professores, evitando problemas ou injustiças e favorecendo que ambos os lados sejam beneficiados com as práticas defendidas pela instituição. Mas pelo trecho não informar quais são essas consequências e em quais regulamentos específicos se encontram as penalidades, as consequências não são tão precisas ou claras quanto deveriam, somente avisam: "há consequências se não forem cumpridas as normas aqui estabelecidas".

$\mathrm{Na}$ instituição observa-se que o regulamento não é inteiramente cumprido, porém raramente se tem notícia de alguma sanção aplicada ao aluno ou ao professor pelo 
não cumprimento de algum dos artigos. Apesar disso, existem alguns casos de processos por parte de discentes quanto ao não cumprimento de algumas normas pelo docente, principalmente aquelas que se relacionam com avaliações e frequência, devido a estas serem diretamente relacionadas a reprovações. Por parte de docentes, processos normalmente se referem a ofensas ou indisciplina de alunos, apesar de não haver nenhum trecho que trate desse tema nessa resolução. Em ambos os casos não se tem conhecimento sobre alguma penalidade efetiva aplicada, tanto para aluno quanto para professor.

\section{Discussão}

De forma geral, foi observado que os seis artigos e o parágrafo analisados descrevem contingências incompletas, isto é, não apresentam os três termos de uma contingência. Cinco artigos e o parágrafo descrevem apenas antecedente e resposta, enquanto apenas um artigo descreve resposta e consequência, indicando, portanto, que a maioria não descreve consequências para o seguimento ou não da regra. A única exceção foi o artigo 64 , que o faz de maneira muito vaga, referindo-se a outros regulamentos específicos da instituição e, ainda, não aponta quais são. Os resultados obtidos nesse trabalho encontram-se de acordo com outros trabalhos da literatura que indicam problemas semelhantes na formulação de leis (ALMEIDA-VERDU et al., 2009; CABRAL, 2011; TODOROV, 1987; TODOROV et al., 2004).

Uma comparação entre o comportamento esperado por cada artigo e a descrição do que normalmente se observa na instituição indicam que a resolução não se mostra inteiramente cumprida, além do fato de ela não ser amplamente divulgada entre alunos e professores, embora contenha elementos pertinentes a respeito de condutas acadêmicas. Uma contingência não especificada claramente dificulta o cumprimento da regra (TEIXEIRA JÚNIOR, 2011; TODOROV et al., 2004), pois, na ausência de uma descrição precisa de seus componentes, o ouvinte pode não saber o que deve ser feito, em que ocasião, ou o porquê. Assim, a falta de descrição de consequências em uma regra pode comprometer o seu seguimento, conforme descrito em estudos da área (MATOS, 2001; PARACAMPO; ALBUQUERQUE, 2005). As consequências do seguimento ou não da regra são especialmente importantes, pois se não vai acontecer nada caso o sujeito não cumpra a regra, ele provavelmente não se dará ao trabalho de cumpri-la. Portanto, “[...] instruções que não con- têm trechos sobre as consequências de não segui-la[s] podem ter o mesmo efeito que a ausência do fornecimento de qualquer instrução." (TEIXEIRA JÚNIOR, 2007, p. 9).

Além da descrição de seus componentes, outro fator importante para o seguimento da regra é verificar se o ouvinte compreendeu a regra a ser seguida. Mesmo que a regra tenha os três termos da contingência, o indivíduo pode não seguir a regra por não tê-la compreendido claramente (ALBUQUERQUE; FERREIRA, 2001). Ou seja, mesmo que ela seja formulada de forma clara e direta, o ouvinte pode não possuir uma história discriminativa que permita responder a ela tal como especificado. Por isso, para que a regra seja cumprida, deve-se também tentar ao máximo estabelecer condições para que o ouvinte a entenda por completo. Repetir a regra várias vezes, especificá-la mais detalhadamente se necessário e pedir para o sujeito descrevê-la com suas próprias palavras, são alguns dos métodos que podem favorecer seu seguimento (TEIXEIRA JÚNIOR, 2007). A esse respeito, um ponto relevante sobre a resolução analisada é que ela não é passada aos alunos, mas, ao se matricularem no curso, eles se comprometem a cumpri-la, ou seja, se comprometem com regras que nem sabem quais são. Isso, aliado com os problemas na formulação de seus trechos, pode ser uma das explicações para o não cumprimento de várias normas institucionais por alunos e professores do curso de Psicologia da instituição.

Aluno e professor são partes essenciais do processo educacional e, desta forma, relacionam-se e exercem controle entre si. Trata-se de uma relação de controle mútuo, na qual ambos são reforçados (SKINNER, 2003). O comportamento do aluno está sob controle do comportamento do professor, que também é controlado pelo comportamento do aluno e ambos também controlam e são controlados pela instituição de ensino. Como agência controladora, ela exerce um controle bastante organizado e preciso sobre o comportamento de seus membros. Então, a proposta de formular uma resolução tem fins didáticos: ela tem o objetivo de prever um melhor cumprimento das regras relativas àquela instituição, assim como leis de maneira geral servem para que o cumprimento de regras seja mais eficiente para uma melhor convivência e sobrevivência daquele ambiente e daquela cultura. Caso contrário, os indivíduos apenas se comportariam de maneira imediatista e até egoísta. As regras existem para facilitar essa convivência, assim como facilitar o aprendizado, de modo que nem todos precisam passar pela mes- 
ma situação para saber como se comportar diante dela, alguém pode dizer: "se fizer desta ou daquela maneira será mais fácil." (BAUM, 2006; CASTANHEIRA, 2001).

Como as regras são úteis na aprendizagem, quando elas não são obedecidas, elas não estão cumprindo sua função. Quando a resolução não é seguida, isso traz prejuízos para os alunos e para os professores: a relação é prejudicada, pois ambos não cumprem plenamente o que deveriam para "uma melhor convivência". Isso afeta a maneira com que professor e aluno se comportam e como se relacionam. Assim, se as regras referentes à instituição não estão claras, diretas e não são ensinadas aos alunos e professores, pode até ser que algumas delas sejam seguidas por alguns indivíduos, porém, dificulta o seguimento por uma quantidade maior de indivíduos, o que gera desorganizações por parte dos membros da instituição, desentendimentos entre eles em forma de processos administrativos, dificuldades de aprendizagem, etc. A esse respeito, por exemplo, Todorov, Martone e Moreira (2006) discutem sobre as novas diretrizes curriculares no ensino. Segundo os autores, novas diretrizes curriculares propostas para os cursos de Psicologia deveriam envolver definições mais claras e específicas dos repertórios comportamentais que o aluno deveria apresentar ao final de sua formação, sendo que na verdade estas são classificadas como muito vagas, criando uma lacuna entre o que deveria ser ensinado e o que de fato é aprendido. Kubo e Botomé (2003) também abordam a falta de objetividade na elaboração de tais diretrizes, o que está diretamente relacionado a como o conhecimento é tratado de maneira subjetiva e, portanto, dificultando o próprio seguimento da diretriz. Para Santos et al. (2009) é necessário diferenciar, por exemplo, os termos "habilidades" (conjunto de comportamentos discretos e observáveis) e "competências" (o grau de eficiência desses comportamentos), usados frequentemente nos artigos dessas diretrizes, de modo que tais conceitos expressos sejam mais claros e precisos para serem eficientes nesse planejamento educacional.

Porém, os aspectos formais da formulação de regras não são uma dificuldade apenas no âmbito educacional. Leis nacionais, estaduais ou municipais mal formuladas ou mesmo desconhecidas pela população são igualmente cobradas. De acordo com o Art. $3^{\circ}$, da Lei de Introdução às Normas do Direito Brasileiro, "Ninguém se escusa de cumprir a lei, alegando que não a conhece." (VADE 2013, p. 139). No caso do regulamento analisa- do, e assim como as diversas leis brasileiras, ele não é apresentado e muito menos ensinado aos alunos e professores, porém, caso tenha algum problema em relação ao seu seguimento, é constado que "está no regulamento". Apesar dos altos índices de analfabetismo no país, ainda assim o Art. $3^{\circ}$ se aplica, ou seja, mesmo sem saber ler ou escrever não se pode alegar desconhecimento da lei.

$\mathrm{Na}$ perspectiva da Análise do Comportamento, tal postura adotada por nossos legisladores não favorece com que leis, regimentos ou resoluções sejam compreendidas e seguidas pelo ouvinte, sem que cuidados com sua formulação e apresentação sejam tomados. Estudos sobre regras têm apontado diversos fatores que afetam esse seguimento, comprovados por trabalhos experimentais e teóricos da área. A elaboração e apresentação de leis e resoluções mais precisas, com base nos princípios da Análise do Comportamento, podem ser mais efetivas no estabelecimento e manutenção do comportamento requerido por elas.

\section{Considerações Finais}

Este estudo buscou compreender, por meio de um exemplo de resolução de uma instituição de ensino superior, como regras sociais podem interferir no comportamento de alunos e professores. Porém, não foi objetivo deste trabalho aprofundar em questões éticas relacionadas ao seguimento de regras, embora seja de conhecimento dos autores que, às vezes, elas podem ser utilizadas de maneira coercitiva ou apenas em benefício dos dirigentes da agência controladora sem a consideração da totalidade de seus membros. Assim, o trabalho não defende o cumprimento de toda e qualquer regra, independente de seu contexto, até porque grande parte de nossas relações poderiam ser melhor controladas face a face, com um contato direto com as contingências. Nesse sentido, discutiu-se alguns fatores que podem afetar o seguimento de regras, avaliando de que forma alternativa elas poderiam ser formuladas para melhorar sua efetividade.

Vale ressaltar que a análise do não cumprimento das regras presentes na resolução deste trabalho foi realizada de forma não sistemática, tendo sido obtida a partir da experiência individual. Desse modo, é necessário considerar a limitação da precisão e generalidade dos dados, uma vez que resultados distintos podem ser obtidos por meio da experiência ou relato de outros alunos ou docentes da instituição. Portanto, pesquisas futuras poderiam dar sequência a essa linha de investigação adotando mé- 
todos mais objetivos como, entrevistas ou questionários, ampliando assim o número de observações e participantes da pesquisa, a fim de comprovar ou confrontar os resultados que foram obtidos em relação ao seguimento de regras em instituições, já que a literatura sobre esse tema específico ainda é escassa.

\section{Referências}

ALBUQUERQUE, L. C. Regras como instrumento de análise do comportamento. In: ALBUQUERQUE, L. C. (Org.). Estudos do comportamento. Belém: UFPA, 2005. p. 143-176.

ALBUQUERQUE, L. C.; FERREIRA, K. V. D. Efeitos de regras com diferentes extensões sobre o comportamento humano. Psicologia: Reflexão e Crítica, Porto Alegre, v. 14, n. 1, p. 143-155, jan./abr. 2001. doi: 10.1590/S010279722001000100012

ALBUQUERQUE, L. C.; PARACAMPO, C. C. P. Análise do controle por regras. Psicologia USP, São Paulo, v. 21, n. 2, p. 253-273, abr./jun. 2010. doi: 10.1590/S010365642010000200004

ALBUQUERQUE, L.C. Definições de regras. In: GUILHARDI, H. J. et al. (Org.). Sobre comportamento e cognição: expondo a variabilidade. Santo André: ESETec, 2001. v. 7. p. 132-140.

ALMEIDA-VERDU, A. C. et al. Descrição e análise de contingências na proposta de estatuto da pessoa com deficiência. In: WIELENSKA, R. C. Sobre comportamento e cognição: desafios, soluções e questionamentos. Santo André: ESETec, 2009. p. 97-110.

BARRETT, D. H. et al. The effects of programmed contingencies and social conditions on responses stereotypy with human subjects. The Psychological Record, Granville, v. 37, n. 4, p. 489-505, oct./nov. 1987.

BAUM, W. M. Compreender o behaviorismo: comportamento, cultura e evolução. Trad. Maria Teresa Araujo Silva et al. 2. ed. Porto Alegre: Artmed, 2006.

CABRAL, M. Contingências e metacontingências na Lei Maria da Penha. 2011. 84 f. Monografia (Graduação em Psicologia)- Universidade Católica de Brasília, Brasília: UCB, 2011.

CALIXTO, F. C. O efeito do histórico comportamental sobre o seguimento de regras disfuncionais. 2009. 44 f. Monografia (Graduação em Psicologia) - Universidade Federal de Mato Grosso do Sul, Mato Grosso do Sul, 2009.
CASTANHEIRA, S. dos S. Regras e aprendizagem por contingência: sempre e em todo lugar. In: GUILHARDI, H. J. et al. (Org.). Sobre comportamento e cognição: expondo variabilidade. Santo André: ESETec, 2001. v. 7. p. 36-46.

CATANIA, A. C. Aprendizagem: comportamento, linguagem e cognição. Trad. Deisy das Graças de Souza. Porto Alegre: Artes Médicas, 1999.

CERUTTI, D. T. Compliance with instructions: effects of randomness in scheduling and monitoring. The Psychological Record, Granville, v. 44, n. 2, p. 51-67, apr./jun. 1994.

KELLER, F. S.; SCHOENFELD, W. N. Princípios de Psicologia. Trad. Carolina Martuscelli Bori; Rodolpho Azzi. São Paulo: EPU, 1973.

KUBO, O. M.; BOTOMÉ, S. P. A transformação do conhecimento em comportamentos profissionais na formação do psicólogo: as possibilidades nas diretrizes curriculares. In: BRANDÃO, M. Z. et al. (Org.). Sobre comportamento e cognição: a história e os avanços, a seleção por consequências em ação. Santo André: ESETec, 2003. v. 11. p. 483-496.

MATOS, M. A. M. Comportamento governado por regras. Revista Brasileira de Terapia Comportamental e Cognitiva, São Paulo, v. 3, n. 2, p. 51-66, dez. 2001.

NICO, Y. Regras e insensibilidade: conceitos básicos, algumas considerações teóricas e empíricas. In: KERBAUY, R. R.; WIELENSKA, R. C. (Org.). Sobre comportamento e cognição: psicologia comportamental e cognitiva - da reflexão teórica à diversidade da aplicação. Santo André: ESETec, 1999. v. 4. p. 31-39.

PARACAMPO, C. C. P.; ALBUQUERQUE, L. C. Comportamento controlado por regras: revisão crítica de proposições conceituais e resultados experimentais. Interação em Psicologia, Curitiba, v. 9, n. 2, p. 227-237, jul./ dez. 2005.

SANTOS, G. C. V. et al. "Habilidades" e "Competências" a desenvolver na capacitação de psicólogos: uma contribuição da análise do comportamento para o exame das diretrizes curriculares. Interação em Psicologia, Curitiba, v. 13, n. 1, p. 131-145, jan./jun. 2009.

SCHLINGER, H.; BLAKELY, E. Function-altering effects of contingency-specifying stimuli. The Behavior Analyst, Kalamazoo, v. 10, n. 1, p. 41-45, jan./jun. 1987.

SKINNER, B. F. An operant analysis of problem solving. In: KLEINMUNTZ, B. (Org.). Problem solving: research, method, and theory. New York: Wiley, 1966. p. 225-257. 
SKINNER, B. F. Ciência e comportamento humano. Trad. João Cláudio Todorov. 11. ed. São Paulo: Martins Fontes, 2003.

SKINNER, B. F. Contingências de reforço: uma análise teórica. (Trad. Rachel Moreno). São Paulo: Abril Cultural, 1980. (Os pensadores).

SKINNER, B. F. Sobre o behaviorismo. Trad. Maria da Penha Villalobos. São Paulo: Cultrix, 2006.

TEIXEIRA JÚNIOR, R. R. Efeitos de instruções preliminares sobre o seguimento de regras. 2011. $76 \mathrm{f}$. Tese (Doutorado em Psicologia) - Universidade Federal do Pará, Pará: UFPA, 2011.

TEIXEIRA JÚNIOR, R. R. Variáveis de controle do comportamento governado por regras: uma análise de métodos e resultados de estudos da área. 2007. 166 f. Dissertação (Mestrado em Psicologia) - Universidade Federal do Pará, Pará: UFPA, 2007.

TEIXEIRA JÚNIOR, R. R.; BRITO, R. C. S.; PARACAMPO, C. C. P. Evolução da cultura humana e suas relações com comportamentos de outras espécies. In: HENRIQUES, A. L. et al. Estudos do comportamento II. Belém: UFPA, 2011.

TODOROV, J. C. A constituição como metacontingência. Psicologia, Ciência e Profissão, Brasília, v. 7, n. 1, p. 9-13, jan./jun. 1987. doi: 10.1590/S1414-98931987000100003
TODOROV, J. C. et al. O Estatuto da criança e do adolescente como metacontingência. In: BRANDÃO, M. Z. et al. (Org.). Sobre comportamento e cognição: contingências e metacontingências, contextos sócioverbais e o comportamento do terapeuta. Santo André: ESETec, 2004. v. 13. p. 44-51.

TODOROV, J. C.; MARTONE, R. C.; MOREIRA, M. B. Novas diretrizes curriculares, metacontingências e o Plano Keller. In: GUILHARDI, H. J.; AGUIRE, N. C. de (Org.). Sobre comportamento e cognição: expondo a variabilidade. Santo André: ESETec, 2006. v. 18. p. 456464.

UNIVERSIDADE FEDERAL DE MATO GROSSO DO SUL. Resolução no 214, de 17 de dezembro de 2009. Boletim Oficial de Atos Administrativos da UFMS. Ano XXI, No 4743, 11 fev. 2010.

VADE Mecum Saraiva: obra coletiva de autoria da Editora Saraiva com a colaboração de Luiz Roberto Curia, Lívia Céspedes e Juliana Nicoletti. 15. ed. São Paulo: Saraiva, 2013.

ZETTLE, R. D.; HAYES, S. C. Rule-governed Behavior: a potential theoretical framework for cognitive-behavioral therapy. In: KENDALL, P. C. (Org.). Advances in cognitive-behavioral research and therapy. New York: Academic Press, 1982. p. 73-118. 